\title{
O PAPEL DOS NÚCLEOS BAIXOS NA INTERPRETAÇÃO DE CAUSALIDADE EM PORTUGUÊS BRASILEIRO: ALGUMAS NOTAS SOBRE DECOMPOSIÇÃO DE EVENTOS, F-SEQ E NANOSSINTAXE
}

\author{
Thayse Letícia FERREIRA* \\ Valdilena RAMMÉ**
}

- RESUMO: Neste trabalho, investigamos o processo de causativização no português brasileiro, buscando compreender as restrições e generalizações que permitem explicar os dados aparentemente caóticos de nossa língua. Para tal, utilizamos o método hipotéticodedutivo e partimos da tese de que são elementos do domínio acional que determinam o comportamento dos verbos em relação à incidência de causalidade. Como consequência, apresentamos neste artigo uma revisão teórica das classes acionais, utilizando ferramentas de um modelo decomposicionista recente denominado Nanossintaxe (STARKE, 2009). Com isso, será possível entender as restrições mais rigorosas que as classes 'estado' e 'accomplishment', por exemplo, impõem para o fenômeno da causativização, levando em conta conceitos sintático-semânticos mais finos, como Iniciação, Processo, Resultado e Limite. Concluímos, deste modo, que para um predicado ser interpretado enquanto causativo faz-se necessário que o evento por ele denotado seja de natureza dinâmica. Além disso, demonstramos que a sequência funcional $(f-s e q)$ da forma como é proposta dentro do modelo nanossintático permite explicar a associação de mais de um nódulo sintático a um mesmo argumento verbal, assim como a sua desassociação e consequente identificação com um núcleo causativo nulo.

- PALAVRAS-CHAVE: Causativização. Decomposição de eventos. Classes acionais. Nanossintaxe. Hierarquia funcional do domínio verbal.

\section{Introdução}

Desde meados da década de 1960, tem-se reconhecido em linguística a necessidade de assumir a existência de elementos em nossa ontologia relacionados a conceitos

\footnotetext{
Universidade Federal de São Carlos (UFSCar), Centro de Educação e Ciências Humanas, São Carlos - SP - Brasil. tleticiaf@gmail.com. ORCID: 0000-0003-2883-8721

** Universidade Federal da Integração Latino-americana (UNILA). Foz do Iguaçu - PR - Brasil. Departamento de Linguística e Letras Modernas. val.ramme@gmail.com. ORCID: 0000-0003-1794-3278.
} 
mais amplos da percepção humana sobre o mundo. Nesse sentido, certos componentes que integram os domínios espacial e temporal, por exemplo, aparecem como traços sintático-semânticos que atuam na construção das gramáticas de língua natural de um modo sistemático. Embora atualmente haja um consenso de que elementos como trajetória, maneira e causalidade sejam relevantes para a construção de sentenças nas línguas naturais, o debate a respeito do locus exato de atuação desses elementos é, ainda, bastante expressivo (RAMCHAND; SVENONIUS, 2014).

Considerando esse quadro, neste trabalho pretendemos investigar um fenômeno relacionado à expressão de causalidade nas línguas naturais, visando, sobretudo, compreender (i) um dos modos pelos quais as diferentes línguas do mundo podem veicular esse tipo de relação e (ii) o papel de diferentes módulos da gramática na construção de um significado causativo. Nomeadamente, investigaremos o fenômeno da causativização, que consiste, grosso modo, em um processo que licencia a atribuição de uma interpretação causativa para predicados ou construções que não veiculam causalidade inerentemente, tal como se observa nos pares de sentença abaixo, em que (a) marca a versão não causativa dos predicados 'pular' e 'emagrecer' e (b) a contraparte causativa dessas mesmas estruturas.

(1) a. O menino pulou pela cerca.

b. A mãe pulou o menino pela cerca.

(2) a. João emagreceu.

b. O remédio emagreceu o João.

Nas sentenças de índice (a), os processos descritos pelos predicados 'pular' e 'emagrecer' ocorrem de um modo "natural" ou "espontâneo", ou seja, nossa interpretação para essas sentenças é simplesmente a de que houve um evento no qual "o menino pulou" e "João emagreceu". Nas sentenças de índice (b), por outro lado, temos uma configuração um tanto quanto inesperada, dado que, nesse caso, interpretamos que os processos denotados por 'pular' e 'emagrecer' não aconteceram de forma natural, mas foram causados pelo argumento localizado na posição de sujeito sintático. Ou seja, entende-se em (1b) que a mãe fez, de algum modo, o menino pular pela cerca e, em (2b), que o remédio fez o João emagrecer. Nessas sentenças, portanto, o evento denotado pelo predicado é, na verdade, o resultado de um outro evento (de causa) desempenhado pelo sujeito.

Esse processo parece ser bastante pervasivo entre as línguas naturais (RAMCHAND, 2008; HORVATH; SILONI, 2011; LYUTIKOVA; TATEVOSOV, 2014), no entanto, é importante notar que: (i) não é a totalidade dos predicados de uma dada língua que pode veicular uma relação de causalidade entre dois eventos (cf. contraste entre as sentenças (1) e (3)); (ii) parece haver restrições específicas de cada língua que bloqueiam a incidência de causalidade sobre seus verbos (cf. sentenças (3) e (4), do português brasileiro (PB) e finlandês, respectivamente); e (iii) a possibilidade de veicular uma 
relação de causalidade se aplica para um certo conjunto de verbos apenas em alguns contextos (cf. sentenças em (5)) ${ }^{1}$.

(3) a. As crianças riram.

b. *O palhaço riu as crianças.

(4) a. Sami naura-tti tyttö-jä.

Sami.nominativo rir-CAUSE.passado meninas-objeto

"Sami riu as meninas" (= Sami fez as meninas rirem)

(Exemplo adaptado de PYLKKÄNEN, 2008)

(5) a. Pedro caiu de cima do muro.

b. *Joana caiu Pedro de cima do muro.

c. O Brasil caiu o índice de analfabetismo.

Ao contrastar os dados exibidos de (1) a (5), podemos nos perguntar qual é a fonte das assimetrias observadas em relação à causativização. Isto é, por que nem todos os verbos (intra ou translinguisticamente) podem ser interpretados enquanto causativos em qualquer situação? Considerando, por exemplo, o contraste entre as sentenças (1) e (3), por um lado, e (3) e (4), por outro, o fenômeno em discussão se torna ainda mais interessante. Dado que tanto o predicado 'pular' quanto o predicado 'rir' pertencem à classe dos verbos inergativos e denotam eventos semelfactivos (ROTHSTEIN, 2004), por que o primeiro pode ser causativizado em português brasileiro sem ruídos na interpretação, ao passo que o segundo é sistematicamente bloqueado a causativizar nessa língua? Ou seja, por que verbos que parecem compartilhar um mesmo conjunto de traços sintático-semânticos exibem um comportamento irregular em relação à incidência de causalidade?

Neste trabalho, objetivamos buscar algumas propriedades sintático-semânticas mais finas dos verbos do PB e dos eventos por eles denotados que talvez possam contribuir para a compreensão do funcionamento do processo de causativização no português brasileiro, visando responder às questões acima elencadas. Para tanto, utilizamos o método hipotético-dedutivo como meio de investigação e aventamos como hipótese de trabalho a tese de que é a arquitetura do segmento da sequência funcional $(f$-seq) que corresponde ao domínio de composição de eventos ("little-v") o fator que restringe a possibilidade de um determinado predicado ser interpretado enquanto causativo

\footnotetext{
Conforme um parecerista anônimo observou, é importante destacar o fato de que não há uniformidade interdialetal em relação aos juízos de boa formação das sentenças causativizadas. Além disso, em certos casos a estrutura causativizada é bastante semelhante a construções de tópico-sujeito. Apesar de tal fato, as sentenças aqui discutidas exibem legitimamente uma interpretação causativa, relacionada ao fato de haver um novo argumento na estrutura que causa o efeito. O principal argumento para defendermos uma leitura causativa para essas sentenças provém justamente de seu significado, que pode ser parafraseado por "x fez VP". Note-se que (5c) pode ser parafraseado por "o Brasil fez o índice de analfabetismo cair", ao passo que em uma construção de tópico-sujeito como "o relógio soltou o ponteiro do minuto" ou "o carro faltou freio" a mesma paráfrase não se aplica: "*o relógio fez o ponteiro do minuto (se) soltar" e "*o carro fez freio faltar".
} 
em nossa língua-objeto, o PB. Para investigarmos nossa hipótese e alcançarmos os objetivos delineados, inserimos a pesquisa no quadro teórico da Nanossintaxe (STARKE, 2009), haja vista que, ao integrar pressupostos do Minimalismo e da Cartografia, o modelo nos oferece um ferramental de trabalho bastante rico, elegante e com poder preditivo, que nos permite olhar para os menores átomos de composição linguística, ensejando, assim, uma compreensão fina da estrutura e do funcionamento do domínio de composição de eventos e de sua relação íntima com as generalizações sobre a estrutura argumental.

Tendo explicitado nossa questão de pesquisa, hipótese e a teoria adotada, apresentamos, na próxima seção, o processo de causativização, discutindo os principais problemas que encontramos na compreensão do fenômeno. Na sequência, exibimos o quadro mais geral da Nanossintaxe (STARKE, 2009; RAMCHAND, 2008; CAHA, 2009) e os principais pressupostos da teoria que embasam nossa análise, desenvolvida na seção "Investigando a causativização no PB dentro da Nanossintaxe", em que confrontamos nossa hipótese de partida com sentenças da língua sob investigação, que terão sua estrutura traduzida para a nomenclatura nanossintática. Ao explorarmos os dados, que aparentam corroborar nossa assunção inicial, argumentamos que são elementos localizados em uma posição baixa na hierarquia funcional que parecem fazer a diferença no comportamento verbal em relação à incidência de causalidade. Além disso, explicamos com as regras de operação nanossintáticas como um significado causativo pode ser alcançado e como a estrutura verbal é reorganizada para tanto. Por fim, demonstramos que há distintos módulos gramaticais atuando para a construção de um significado causativo. Na sequência, tecemos algumas conclusões sobre as ideias discutidas neste trabalho. Com isso, esperamos contribuir com a descrição do PB e com os estudos sobre a expressão de causalidade nas línguas naturais, abrindo, também, uma nova perspectiva para a investigação da causativização.

\section{Licenciando uma interpretação causativa para predicados não causais: o fenômeno da causativização}

A relação de causalidade tem sido um tópico de investigação constante nos estudos linguísticos. Conforme é possível observar em textos seminais tais como Dowty (1979), Parsons (1990), Levin e Rappaport-Hovav (2005), Kratzer (2005), Ramchand (2008) e Higginbotham (2009), essa relação parece ser central para nossa compreensão a respeito de questões sobre o domínio acional e sobre a interface entre sintaxe e semântica. De acordo com Copley e Wolff (2014, p.11, tradução nossa), “[...] muito da estrutura frasal é organizada em torno dos eventos (ou entidades semelhantes aos eventos, tais como as situações) e de suas relações causais" ". Como consequência dessa afirmação,

\footnotetext{
No original: "[...] much of phrase structure is arranged around causal relationships between events (or event-like entities such as situations)".
} 
pautada em observações empíricas, podemos dizer que investigar os mecanismos utilizados pelas diferentes línguas para expressar causalidade é um passo importante para a compreensão de diversos fenômenos.

A causalidade, aqui, pode ser entendida como uma relação entre dois eventos: uma causa e um efeito (DAVIDSON, 1967; LEWIS, 1973), organizados de tal modo que o efeito não deve preceder naturalmente a causa. Isto é, a menos que tratemos de viagens no tempo ou de eventos quânticos, casos em que se manipula explicitamente a sequência dos acontecimentos, a ordenação natural dos relata causais é dada por "causa $\rightarrow$ efeito". Se, por exemplo, admitimos que uma sentença como "Joana quebrou a janela" expressa uma relação de causalidade, então devemos entender que Joana fez algo em $t 1$ que teve como resultado "o quebrar da janela" em $t 2$. Ou seja, não importa se Joana arremessou uma pedra em direção à janela ou deu uma martelada nesse objeto; dado um evento de causa, sua ocorrência deve ser anterior ao efeito, explicitado, nesse caso, por "o quebrar da janela". Tal fato, ainda que apresentado brevemente, nos leva a inserir um parâmetro de temporalidade na definição do que seja causalidade, em consonância com os trabalhos de Aguiar (2003), Schaffer (2016) e Neeleman e van de Koot (2012) ${ }^{3}$.

Em linguística, a relação de causalidade é normalmente representada pelo predicado CAUSA (JACKENDOFF, 1983; PINKER, 1989) e a ordenação temporal entre os eventos pode ser garantida por um par ordenado como $<$ causa, efeito $>$. Desse modo, quando se fala em uma interpretação causativa das sentenças, assume-se que um elemento do tipo CAUSA $<$ causa, efeito $>$ integra o conjunto de itens que compõem sua estrutura. Quando ocorre o processo de causativização, portanto, é todo esse componente que passa a ser computado no significado global da sentença. Conforme discutimos na introdução, não são todos os verbos de uma dada língua que podem ser interpretados enquanto causativos, ou seja, nem todos os verbos permitem a inserção de um elemento CAUSA < causa, efeito $>$ em sua composição. Considerando esse fato, tomemos as sentenças abaixo para compreendermos quais são os problemas encontrados na análise da causativização em PB.

(6) a. Joana acordou.

b. O despertador/Pedro acordou a Joana.

(7) a. A nota do programa subiu.

b. Os professores subiram a nota do programa.

Os predicados 'acordar' e 'subir' pertencem à classe dos verbos inacusativos, dado que permitem um uso adjetival em construções de particípio passado (PPA constructions) (SILVA, 2009) (cf. (8) abaixo) e bloqueiam a formação de nominalizações em '-(d)or'

\footnotetext{
Há, ainda, alguns autores que admitem que a relação de causalidade depende, também, de um parâmetro de contrafactualidade, dado que a temporalidade parece ser condição necessária, mas não suficiente para definir essa relação. Entende-se, manipulando-se um parâmetro de mundo possível, que se a causa não ocorre, o evento de efeito também não ocorre $(\neg \mathrm{O}(c) \bullet \rightarrow \neg \mathrm{O}(e))$. Neste trabalho, não exploramos a contrafactualidade, no entanto, remetemos o leitor interessado aos trabalhos de Dowty (1979), Eckardt (2000) e Kratzer (2005).
} 
(cf. (9) abaixo), mecanismo que opera livremente sobre predicados inergativos, que exibem em sua estrutura um único argumento externo, normalmente associado a um papel de agentividade no desenrolar do evento.

(8) a. A Joana acordada fica muito irritada.

b. Os arquivos subidos pelos usuários são criptografados.

(9) a. *Pedro é acordador de gente preguiçosa.

b. *Os subidores de arquivo chegaram ${ }^{4}$.

Esses testes indicam que o único argumento que esses verbos contêm em sua estrutura - (6a) e (7a) - é um objeto direto, um argumento interno à camada do VP. Quando essas sentenças são causativizadas, contudo, nota-se que um novo argumento surge na sentença na posição de sujeito sintático. Tendo em vista esse fato, poderíamos, em princípio, aventar a hipótese de que inacusativos causativizam porque contêm um núcleo sintático disponível para receber um novo argumento ([spec-vP] ou [voiceP]), desencadeando assim, uma interpretação de causalidade. No entanto, esse não é sempre o caso, dado que não são todos os predicados inacusativos que podem causativizar - cf. (10) - e, além disso, verbos inergativos, que já contêm um argumento na posição de spec-vP ou voiceP, podem licenciar o processo em questão, conforme as sentenças em (11) demonstram, com o verbo 'mergulhar's.

(10) a. Joana saiu de casa.

b. *Alice saiu Joana de casa.

(11) a. A criança mergulhou no rio.

b. Tétis mergulhou a criança no rio.

Observando os exemplos oferecidos, explicar o processo de causativização de inergativos parece ser um tanto mais complicado do que compreender a causativização de predicados inacusativos, pois há uma reorganização transparente da estrutura argumental do verbo: em (11b), com o surgimento do argumento 'Tétis' na sentença, o argumento original do verbo, 'a criança', é, de algum modo, deslocado para a posição de objeto direto, a qual é, alegadamente, um espaço funcional não disponível para esse

4 Em uma pesquisa rápida em motores de busca como o Google, é possível, na verdade, encontrar alguns usos de 'subidor'. No entanto, é importante notar que os falantes normalmente utilizam essa nominalização entre aspas, o que indica que o uso em questão é feito por meio de uma manipulação consciente de regras subjacentes da língua. Um exemplo dessa ocorrência pode ser dada por “[a] capacitação é voltada para os 'subidores' de coqueiro [...]”, disponível em: http://www.alagoas24horas.com.br/709551/trabalhadores-sao-capacitados-para-coleta-do-coco/. Nesse caso, é interessante notar também que o uso de 'subir' se assemelha ao de um verbo inergativo, em que o indivíduo atua no evento com intencionalidade e controle sobre suas ações ou, mais especificamente, o indivíduo que inicia o evento é o mesmo que é afetado por ele.

5 Prova de que o verbo 'mergulhar' é, verdadeiramente, um predicado inergativo é o fato de permitir a criação de um substantivo em '-(d)or', como 'mergulhador', e bloquear a formação de particípio passado com uso adjetival, como em "*a criança mergulhada sorriu". 
tipo de predicado ${ }^{6}$. Além disso, nesse caso, o argumento deixa de desempenhar um papel agentivo no evento e passa a ser afetado, de algum modo, pelo evento desempenhado pelo sujeito.

O que os exemplos de (8) a (11) evidenciam, portanto, é que embora a causativização pareça envolver algum tipo de alternância argumental, o que temos é, na verdade, um fenômeno distinto, que independe da grade argumental intrínseca dos verbos. Apesar desse fato, não podemos negar que o fenômeno em análise apresenta claramente um problema de estrutura argumental, pois quando a causativização é licenciada, há (i) a inserção de um novo evento na estrutura, interpretado como a causa que leva ao evento denotado pelo predicado; (ii) surge um novo argumento com o papel de "causador" ou "iniciador" da eventualidade descrita pelo predicado principal, associado ao evento causa; e, como consequência do aparecimento desse outro argumento, (iii) relações temáticas atípicas são estabelecidas entre o sujeito e o objeto direto do predicado. Como explicar a existência de todas essas novas relações quando um dado predicado é causativizado?

Em português brasileiro, trabalhos anteriores já buscaram responder a essa mesma questão, contudo, apesar de isolarem algumas propriedades descritivas do processo de causativização nessa língua, acabam não alcançando um nível explicativo de fato sobretudo para as relações observadas (AMARAL, 2009; CAMBRUSSI, 2009; SILVA, 2009; FERREIRA; RAMMÉ, 2014). As pesquisas desenvolvidas por Cambrussi (2009, 2015) e Amaral (2009), por exemplo, ambas elaboradas no quadro da semântica léxicoconceitual de Jackendoff (1983) e Levin e Rappaport-Hovav (2005), destacam certas propriedades temáticas como sendo responsáveis pelo comportamento dos verbos do PB em relação à causativização, mas não demonstram quais são as regras necessárias para que uma interpretação causativa possa ser alcançada nesse quadro de trabalho. A título de exemplificação, podemos tomar o trabalho de Cambrussi $(2009,2015)$ como arquétipo desse tipo de pesquisa: ao investigar a causativização de inergativos, a autora propõe que apenas verbos que denotam um estado internamente causado e que permitem indução externa, mantendo a relação semântica de desencadeador entre o verbo e seu único argumento da versão intransitiva, podem ser interpretados enquanto causativos. No entanto, além de encontrarmos contra-exemplos para a restrição sugerida, conforme as sentenças abaixo ilustram, Cambrussi $(2009,2015)$ não discute quais regras podem explicar a manipulação pela qual os predicados inergativos passam para que adquiram uma estrutura que será interpretada enquanto causativa, o que é essencial para que se compreenda o fenômeno da causativização em sua completude.

(12) a. *Joana tossiu o bebê.

b. *Pedro chorou o João.

6 Para uma visão contrária à ideia de que inergativos têm um único argumento do tipo externo, ver Hale e Keyser (1993). 
Considerando que tanto 'tossir' quanto 'chorar' sejam verbos inergativos que denotam estados internamente causados, por se tratarem de processos corporais, $\mathrm{o}$ papel de desencadeamento do evento seria necessariamente mantido para o argumento original do predicado. Afinal, para que os eventos de 'tossir' e 'chorar' ocorram, obrigatoriamente quem os desencadeia e desempenha é a pessoa que 'tosse' e 'chora'. Ou seja, por mais que as sentenças em (12) respeitem as propriedades elencadas por Cambrussi (2009) como sendo suficientes e necessárias para o licenciamento do processo de causativização, o fenômeno é bloqueado para esse tipo de predicado. Ademais, não há uma explicação para como um novo argumento pode ser inserido e computado nesse tipo de estrutura, em que alegadamente tem-se apenas uma posição argumental a ser preenchida.

Neste trabalho, além de buscarmos propriedades mais finas do evento como sendo responsáveis pelo comportamento dos verbos em relação à causativização, que podem não estar relacionadas a propriedades temáticas do verbo, tal como defendido por trabalhos anteriores (CAMBRUSSI, 2009, 2015; AMARAL, 2009), pretendemos preencher a lacuna explicativa a respeito da composição das estruturas que podem ser interpretadas como causativas. Por conta disso, acreditamos que mobilizar uma teoria que trate de eventos e da organização sintática dos argumentos verbais, considerando uma relação direta entre semântica e sintaxe, possa ser mais vantajoso para nos ajudar a clarificar o funcionamento da causativização e compreender por que apenas alguns verbos podem licenciar esse fenômeno. O modelo explorado nesta pesquisa, a ser discutido na próxima seção, se apresenta como um modelo promissor para que alcancemos os objetivos delineados, pois dispõe de regras para a derivação da estrutura, que são independentemente motivadas, além de tratar-se de uma abordagem computacionalmente mais econômica em relação aos modelos mais clássicos existentes no âmbito da sintaxe gerativa. Conforme veremos na sequência, a Nanossintaxe (STARKE, 2009) desloca uma série de hipóteses auxiliares do gerativismo, tais como as teorias temática e de caso, para a sequência funcional universal $(f$-seq). Desse modo, como se assume no modelo a existência de um grande conjunto de ingredientes de composição linguística, seria esperado encontrar nas línguas naturais tantas estruturas quanto combinações de traços possíveis. Para evitar essa sobregeração de estruturas, o modelo postula regras rígidas para a derivação adequada da hierarquia, o que torna a teoria empiricamente adequada. Tendo em vista algumas das vantagens em se explorar a Nanossintaxe como modelo de gramática, na próxima seção, apresentamos o quadro teórico no qual esta investigação se insere.

\section{O quadro teórico: nanossintaxe e decomposição de eventos}

A Nanossintaxe é uma nova teoria sobre a arquitetura da gramática que busca em níveis granulares os diferentes blocos de composição linguística. A questão fundamental que levou à criação dessa teoria no "Centro para Estudos Avançados em Linguística 
Teórica" (CASTL) ${ }^{7}$, da Universidade de Tromsø, consiste na observação empírica de que as representações sintáticas desenvolvidas nos últimos trinta anos têm utilizado ingredientes cada vez menores em sua composição, dando origem a estruturas cada vez maiores e mais articuladas. De acordo com Starke (2009), esse fato contradiz um dos dogmas fundamentais do campo, a saber, a conjectura de que a sintaxe é apenas um modo de organizar o léxico em estruturas complexas. Assim, considerando a existência de tal contradição e o fato de que diversas pesquisas demonstraram nas últimas décadas que a sintaxe opera, na verdade, com elementos não lexicais, menores do que um morfema (HALLE; MARANTZ, 1993; MARANTZ, 1997; EMBICK, 2015, entre outros), a Nanossintaxe assume que a natureza dos ingredientes de composição linguística é submorfêmica.

Note-se que a ideia central da Nanossintaxe não é inaugural da teoria. Desde meados da década de 1990 a Cartografia desenvolvida por Rizzi (1997), Cinque (1999), Belleti (2004) e Cinque e Rizzi (2008) já trabalha com a mesma concepção. Por conta disso, a Nanossintaxe pode ser tomada como um modelo de inspiração cartográfica que acaba assumindo como metodologia de trabalho a heurística proposta por Kayne (2005), conhecida pela máxima "um traço-um núcleo". Essa observação pode levar a crer que não há qualquer vantagem em se utilizar a Nanossintaxe para a investigação dos fenômenos linguísticos, uma vez que esse modelo se preocupa em mapear a hierarquia dos núcleos funcionais que compõem os mais diversos domínios linguísticos, tais como DP, CP, IP, vP e KP, analogamente ao trabalho desenvolvido em Cartografia (SHLONSKY, 2010). No entanto, essa total coincidência entre os modelos é apenas aparente, pois a Nanossintaxe (CAHA, 2009) ultrapassa a Cartografia ao propor regras de derivação rígidas que irão se impor sobre a hierarquia funcional universal (f-seq). Se metodologicamente a Nanossintaxe se aproxima da Cartografia, quando pensamos em seu diferencial, isto é, nas regras de composição estrutural, encontramos paralelos entre esta e a Morfologia Distribuída (HALLE; MARANTZ, 1993).

Para Caha (2009), o principal fundamento teórico da Nanossintaxe consiste na ideia de que a sintaxe não é apenas um modo de construir sintagmas complexos e sentenças com base em uma lista de itens arquivados no léxico (morfemas e palavras); pelo contrário, nesse modelo, a sintaxe é tida como o único e verdadeiro componente gerativo que aplica uniformemente as mesmas regras aos traços submorfêmicos, morfemas, palavras e sintagmas, podendo, desse modo, construir elegantemente sentenças em língua natural, utilizando apenas um pequeno maquinário que garante a adequação explanatória da teoria. Como consequência dessa centralidade da sintaxe na computação, a Nanossintaxe é, assim como a Morfologia Distribuída (MD), um sistema de inserção tardia, e é por esse motivo que os paralelos técnicos estabelecidos entre esses dois modelos são inevitáveis (CAHA, 2018). Apesar desses pontos em comum entre os modelos, a Nanossintaxe é distinta da MD, grosso modo, por excluir do sistema a necessidade de se postular regras e operações pós-sintáticas, tais como

Center for Advanced Study in Theoretical Linguistics (CASTL). 
a fissão, fusão, o empobrecimento e a deleção de traços, o que torna todo o sistema mais simples e econômico do ponto de vista computacional. Além disso, a perspectiva do que seja o léxico é também distinta nesses dois modelos: enquanto a MD trabalha com feixes de traços distribuídos em diferentes listas no léxico, a Nanossintaxe toma apenas os traços submorfêmicos individualmente armazenados como sendo os blocos de composição básica. Como a sintaxe nesse modelo constrói os morfemas, não há como tomar uma porção de morfemas armazenados em um léxico pré-sintático como primeiro input de composição.

Muito provavelmente, a concepção de léxico da Nanossintaxe seja o fator que mais possa distinguir esse modelo de outros já bem estabelecidos em sintaxe gerativa. De acordo com Ramchand (2008), o léxico passa a ser nessa teoria um locus de unificação transmodular, pois, por não apresentar regras próprias de derivação, tal como modelos lexicalistas propõem (JACKENDOFF, 1983; PINKER, 1989; LEVIN; RAPPAPORT-HOVAV, 2005), apenas arquiva informações construídas em outros componentes. Especificamente, uma entrada lexical é uma tripla ordenada do tipo </informação fonológica/, informação estrutural SMS, informação enciclopédica>, sendo que a "informação estrutural SMS" corresponde a pedaços da $f$-seq universal construída pela sintaxe, de tal modo que carrega informação sintática ( $\mathrm{PP}=$ preposição), morfológica $(\mathrm{KP}=$ caso) e semântica $(\mathrm{EvtP}=$ evento). Note-se que o fato de o léxico ser um repositório de informações (e não um componente da gramática dinâmico com regras de composição) não exclui sua importância para a derivação, posto que a informação que ele armazena deve ser compatível com a estrutura construída pela sintaxe para que um dado item possa identificar uma dada sequência de núcleos funcionais na estrutura. Como neste trabalho estamos buscando propriedades do domínio de construção de eventos que possam ser relevantes para o licenciamento da causativização, podemos entender melhor como a derivação ocorre na Nanossintaxe e o papel que o léxico desempenha nessa teoria discutindo, primeiramente, a hierarquia nanossintática que tem sido proposta para esse domínio.

De acordo com Tenny e Pustejovsky (2000), podemos dizer que foi em meados dos anos 1990 que os sintaticistas passaram a se preocupar em compreender o papel da estrutura do evento na organização da estrutura sintática. Nesse quadro, trabalhos como os de Travis (1994) e Ramchand (2008) argumentaram que a estrutura acional estava diretamente codificada na estrutura sintática e propuseram, assim, que o significado dos verbos fosse construído composicionalmente a partir de primitivos ligados aos núcleos funcionais sintáticos e às raízes verbais abstratas (DÖLLING, HEYDE-ZYBATOW; SCHÄFER, 2007). Embora essa ideia seja amplamente aceita atualmente, por considerar o papel central da composicionalidade na construção das sentenças de língua natural e a existência de uma hierarquia funcional rígida, ainda há um grande debate na literatura a respeito de quais elementos da estrutura do evento devem ser representados na estrutura sintática, enquanto núcleos funcionais, e quais elementos devem ser vistos ou como um epifenômeno da composição estrutural ou como pertencendo a outros domínios da gramática e da cognição humana de um modo mais geral. 
No âmbito da Nanossintaxe, é o trabalho de Ramchand $(2008,2011,2017)$ que busca uma solução para os problemas elencados acima. Com base na observação de que a camada sintagmática "verbo" é, na verdade, uma abreviação para uma estrutura funcional muito mais rica (D’ALESSANDRO; FRANCO; GALLEGO, 2017), Ramchand (2008) propõe a existência de uma estrutura mais articulada para o domínio verbal (vP), o qual é, segundo a autora, “[a] parte da representação de língua natural que corresponde [...] ao núcleo de construção de eventos" (RAMCHAND, 2017, p. 233 , grifo do autor, tradução nossa $)^{8}$. A estrutura do $v \mathrm{P}$ arquitetada por Ramchand (2008) se configura, assim, como um modelo para o domínio de construção de eventos, denominado pela autora como "Sintaxe de Primeira Fase", haja vista que há uma prioridade lógica da porção de construção do evento denotado por uma proposição em relação à computação de outros elementos, como concordância e marcação de caso, por exemplo.

$\mathrm{Na}$ Primeira Fase, as generalizações selecionais são vistas como submissas à representação em termos de uma sintaxe articulada com uma interpretação semântica sistemática. Como esse sistema é desenvolvido com base em pressupostos da Nanossintaxe, há uma simplificação radical da arquitetura da gramática, uma vez que o léxico é eliminado como um módulo independente, com regras e operações próprias, e o núcleo computacional é deslocado integralmente para a sintaxe, o que limita a flexibilidade do item verbal e as generalizações a seu respeito a esse único componente. Podemos dizer, desse modo, que a competência linguística é representada por um único sistema combinatório a partir do qual as sentenças são construídas com apenas um conjunto de traços primitivos e um conjunto de operações.

Para Ramchand (2017), a tarefa de apreender adequadamente quais itens compõem esse conjunto de traços formais da computação deve ser semanticamente baseada, afinal, o núcleo computacional da linguagem humana não apenas concatena sintagmas respeitando a ordenação sintática específica de línguas particulares, mas há, também, um componente de interpretação que atua fortemente sobre esse núcleo estabelecendo, sobretudo, uma relação entre o processamento linguístico prescrito pela gramática universal (GU) e os fatos do mundo. Por conta disso, a autora propõe que os traços acionais submorfêmicos sejam baseados na noção de causação. Segundo a autora, como os falantes percebem os eventos em termos de um desencadeamento que causa um processo e culmina em um resultado, parece ser seguro pensar na configuração dos traços do domínio verbal como uma generalização dessa intuição, baseada em uma dinâmica de forças (TALMY, 2000). Desse modo, Ramchand (2008) propõe três elementos aspectuais fundamentais para a composição eventiva: iniciação [init], processo [proc] e resultado [res], que são organizados hierarquicamente em uma representação sintática, tal como se observa na Figura 1.

No original: "[...] part of the natural language representation corresponds to [...] the core event building domain". 
Figura 1 - A Nanossintaxe do domínio acional

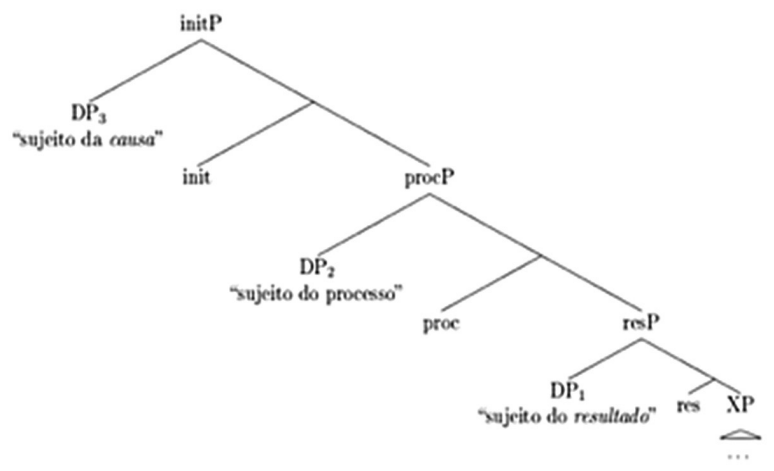

Fonte: Ramchand (2008, p. 39).

Essa representação arbórea é, conforme dissemos anteriormente, uma geometria de traços articulada para o domínio de construção de eventos ${ }^{9}$. Os traços [init], [proc] e [res] e suas projeções são análogos aos diferentes "sabores de vezinho (v)" (flavors of $v$ ) e a denotação do $v \mathrm{P}$ pode ser dada por um conjunto de eventos, representado pelos sintagmas "initP", "procP" e "resP". A projeção initP rotula, desse modo, qualquer estado inicial ou evento de causa que possa desencadear um processo, descrito por procP, núcleo de um predicado dinâmico, que expressa uma mudança de propriedade. Quando essa mudança pode levar à existência de um estado final (que é consequência necessária do processo em questão), a estrutura pode também ser identificada pelo sintagma resP.

Considerando que a motivação semântico-conceitual é fundamental, mas não se sustenta sozinha, Ramchand (2008) discute também evidências morfossintáticas de línguas não relacionadas para respaldar sua proposta e promover os traços apresentados. Segundo a autora, uma motivação sintática para o traço iniciação [init] se encontraria nas alternâncias de transitividade que são licenciadas por certos verbos. Por exemplo, verbos como "quebrar" permitem uma versão transitiva (13a) e outra intransitiva (13b), enquanto que verbos como "jogar" bloqueiam a estrutura em que a informação sobre a iniciação do processo [init] estaria ausente, como (14b) abaixo:

(13) a. Joana quebrou o pauzinho.

b. O pauzinho quebrou.

(14) a. Joana jogou o pauzinho.

b. *O pauzinho jogou.

9 De acordo com Ramchand (2008, 2019), essa complexidade interna dos eventos é motivada e apoiada por trabalhos como os de Vendler (1957), Parsons (1990), Pustejovsky (1991), Krifka (1998) e Higginbotham (2009), que procuram evidenciar a existência de traços mais finos na composição de cada classe acional, tais como [ $\pm_{\text {dinamicidade], }}$ [ \pm duratividade], e [ \pm télico]. 
Além disso, Ramchand (2008) apresenta dados do hindi em que observamos como o sentido de causa/iniciação pode ser acrescentado a um evento, através da realização sintática de um morfema com o traço [Init] junto à raiz do verbo, sem que um novo argumento seja, necessariamente, incluído na equação:

(15) a. makaan ban-aa

house make-PERF.M.SG

'The house was built.'

b. anjum-ne (*mazdur ${ }^{\sim}$ o-se) makaan ban-ạ-yaa

Anjum-ERG (*labourers-INSTR) house make-aa-PERF.M.SG

'Anjum built a house.'

c. anjum-ne (mazdur ̃-se) makaan ban-vaa-yaa

Anjum-ERG house make-vaa-PERF.M.SG

'Anjum had a house built (by the labourers).'

Já a motivação morfossintática para a existência de um subevento denominado processo encontra-se nas diferentes possibilidades de modificação que certos predicados dinâmicos permitem, como é evidenciado, por exemplo, pelo teste da inserção do adjunto 'por x tempo' em uma estrutura, possibilitando a interpretação de um evento que se desenrola no tempo:

(16) Joana dançou por horas.

(17) *Joana soube por horas.

Finalmente, uma das evidências morfossintáticas para a proposta de uma projeção resP abaixo de procP vem de línguas como o inglês, em que também são encontrados morfemas ou partículas que, quando acrescentados a eventos dinâmicos, indicam que o limite ou estado final de um evento foi necessariamente atingido. Nas sentenças de índice (b) abaixo, por exemplo, a partícula "up" indica que a mesa foi limpa ou que o cheesecake foi comido na sua totalidade.

(18) a. Joana cleaned the table.

Joana limpou a mesa.

b. Joana cleaned the table up.

Joana limpou a mesa todinha.

(19) a. Joana ate the cheesecake.

Joana comeu o cheesecake.

b. Joana ate the cheesecake up.

Joana comeu o cheesecake todinho. 
Em adição à tripartição eventiva apresentada acima, é possível que os predicados apresentem ainda complementos que atuam como modificadores das projeções centrais, embora não carreguem um conteúdo eventivo ou acional, tal como [init], [proc] e [res]. Esses modificadores, que atuam na estrutura como parte da descrição do evento, podem ser de dois tipos, segundo Ramchand (2008): trajetória [path] e rema [rheme]. O primeiro núcleo pode ser encontrado como complemento do componente dinâmico (procP) e é interpretado como uma propriedade que determina a trajetória/rota de mudança pela qual o argumento de procP passa, estabelecendo, desse modo, uma relação mereológica (de parte-todo) com o evento. O segundo, rema, pode aparecer como complemento das projeções [init] e [res], acrescentando à estrutura propriedades que têm relação com o estado inicial ou final do objeto que carrega ou sofre o estado/ processo denotado pelo verbo.

Como, neste trabalho, somente os complementos de procP serão explorados, deixaremos de lado, por questão de espaço, um aprofundamento na discussão das motivações morfossintáticas e semânticas do modificador rema ${ }^{10}$. Contudo, é importante destacar as características do argumento trajetória, uma vez que ele ocupa a posição de modificador de procP. Para Ramchand (2008), a existência de [path] é justificada pela necessidade de se fazer a distinção entre complementos de verbos dinâmicos que podem ora ser rotulados como argumentos de procP e ora como argumentos de pathP, uma vez que ambos podem ser encontrados na mesma sentença, além de serem interpretados, sistematicamente, de forma distinta. Assim, em (20) abaixo, observamos que, enquanto "Joana" é o argumento que desempenha (undergoes) o processo denotado pelo verbo, o complemento direto "duas piscinas" é interpretado com uma trajetória que se relaciona homomorficamente ao argumento UNDERGOER (Joana) e define, assim, o tempo e espaço do evento:

\section{(20) Joana nadou duas piscinas.}

Tendo apresentado e motivado empiricamente os elementos que compõem o domínio acional, os testes que podem capturar a presença desses traços na estrutura do evento são aqueles reconhecidos na literatura tempo-aspectual: como os estados representam a única classe não dinâmica [-processo] na tipologia dos eventos, somente essa classe é incompatível com a expressão 'fazer o mesmo' (BASSO, 2007) e gera sentenças agramaticais com o verbo aspectual 'continuar' (LUNGUINHO, 2005), conforme podemos observar nas sentenças abaixo ${ }^{11}$. Consequentemente, na Nanossintaxe, estados

10 Como observado, a distinção entre 'path' e 'rheme' consiste no tipo de núcleo com o qual esses elementos podem se combinar. O elemento 'path' pode entrar em composição com predicados dinâmicos, que exibam [proc] na estrutura, ao passo que 'rheme' é uma espécie de modificador de núcleos não dinâmicos [init, res], trazendo informações novas, que complementam o significado do evento, mas não necessárias para sua construção. A parte "remática" da estrutura, portanto, pode ser preenchida apenas por adjuntos que possam modificar eventos. Para maiores detalhes sobre essa distinção, sugerimos a leitura de Ramchand (2008, 2017), que desenvolve detalhadamente as ideias aqui expostas.

11 Todos os testes apresentados são veiculados no perfectivo e com objetos singulares. A composição, por exemplo, de adjuntos como 'em x tempo' em sentenças imperfectivas e com objetos plurais leva a uma série de outras interpretações 
contêm apenas o traço de iniciação, podendo ter um complemento não dinâmico do tipo rema, e todos os demais eventos, dinâmicos, carregam o núcleo de processo [proc], adequadamente capturado pelos testes sugeridos.

(21) *Joana sabe inglês e Pedro faz o mesmo.

[estado]

(22) Joana corre no parque e Maria faz o mesmo.

[atividade]

(23) *Joana continuou a saber inglês.

[estado]

(24) Joana continuou a construir a casa.

[accomplishment]

O traço de duratividade, relacionado à ausência do núcleo de resultado [res], pode ser capturado por outro teste, nomeadamente, a inserção na sentença de um adjunto como 'por x tempo' (BASSO, 2007; BASSO; PIRES DE OLIVEIRA, 2010):

(25) \#Pedro caiu por 10 minutos.

(26) Pedro estudou por 10 minutos. [achievement $]^{12}$

[atividade]

A respeito do traço de telicidade, Ramchand (2008) não propõe uma posição específica na hierarquia para esse terminal. Na verdade, no trabalho da autora, [res] exerce uma dupla função dentro da estrutura, estando ora responsável por veicular a telicidade do evento e ora a ideia de pontualidade existente em predicados achievements e semelfactivos. A proposta da autora nos traz explicitamente três problemas: (i) os verbos semelfactivos são, na verdade, atélicos (SMITH, 1997) (cf. “*a Maria tossiu em 10 minutos"), (ii) não há como saber quando o terminal [res] veicula exclusivamente telicidade e quando veicula exclusivamente pontualidade e (iii) considerando que a Nanossintaxe é um ramo da Cartografia (CINQUE, 1999), assumir que um mesmo núcleo carrega dois traços ([+télico] e [+pontual]) fere a máxima "um traço, um núcleo", central para o desenvolvimento das hierarquias. Por conta desses fatos, propomos neste trabalho uma pequena modificação da estrutura de Ramchand (2008) e inserimos o traço [bound] na hierarquia acional ${ }^{13}$, logo abaixo do traço [res], o que mapeia a hierarquia apresentada em (27) e pode ser capturado pelo teste da inserção do adjunto 'em $\mathrm{x}$ tempo’ na estrutura (BASSO, 2007).

(27) initP $>$ procP $>$ resP $>$ boundP

Essa proposta se adéqua, teoricamente, à preocupação nanossintática em representar cada elemento relevante para a composição linguística enquanto um núcleo funcional

para a estrutura do evento que não são alvo de investigação neste trabalho.

12 Há uma interpretação possível para a sentença (25), na qual o advérbio opera sobre uma espécie de fase resultante do evento, que captura a ideia de que "Pedro caiu $e$ ficou caído por 10 minutos". Essa possibilidade de leitura para uma sentença pontual com 'por x tempo' foi observada por Basso (2007, p. 147).

13 Rotular esse núcleo como "limite" e não "telicidade" não é uma manobra gratuita, pois trajetórias e escalas apresentam, analogamente à telicidade, uma fronteira final (upper-bound). 
independente e, empiricamente, à existência de uma série de morfemas encontrados em diferentes línguas que introduzem telicidade na sentença (PIÑON, 2001; RAMCHAND, 2008; BORER, 2005; entre outros), como 'z-' no polonês, certos verbos leves como 'jana' no hindi (BHATT; PANTCHEVA, 2005) e '-eci' no coreano (LIM; ZUBIZARRETA, 2012). Com isso, é possível explicar, por exemplo, a possibilidade de predicados que denotam degree achievements poderem ora exibir telicidade e ora não (cf. sentenças em (27)).

(27) a. A roupa secou por duas horas.

[atélico]

b. A roupa secou em duas horas.

[télico]

$\mathrm{O}$ fenômeno apresentado pode ser justificado à medida que a Nanossintaxe assume uma versão "leve" da cartografia, permitindo, assim, que alguns terminais possam ser ignorados na computação, desde que respeitem uma série de regras rígidas do processo de Spell-out. A regra que explicaria a omissão de [bound] na estrutura é denominada Condição de Âncora (The Anchor Condition) e estabelece justamente que o traço mais baixo de uma determinada hierarquia atua como a âncora da estrutura, devendo ser necessariamente identificado na operação de Spell-out (CAHA, 2009; PANTCHEVA, 2011). Essa condição pode ser facilmente observada nos diferentes significados atribuídos ao verbo 'dar', exemplificados abaixo, em que é possível ocultar os núcleos mais altos da estrutura, o que resulta em diferentes interpretações, mas não o mais baixo, o que torna a sentença (29) agramatical.

(28) a. Joana deu um chute na porta.

[iniciação $>$ processo $>$ resultado]

b. 10 menos 2 dá 8 .

[processo $>$ resultado]

c. Deu duas horas.

[resultado]

(29) *10 menos 2 dá.

[processo]

Alegadamente, o traço mais baixo de um evento degree achievement seria o núcleo de escala [scale], presente também em adjetivos dimensionais, como 'alto' e 'baixo'. Logo, esse núcleo não pode ficar sem computação na derivação, devendo ser realizado obrigatoriamente, o que permite que [bound] seja ocultado. Essa operação que ignora itens na derivação é denominada Subassociação (Underassociation) (RAMCHAND, 2008) e será explorada na explicação do fenômeno da causativização no PB.

Conforme dissemos anteriormente, na Nanossintaxe, hipóteses auxiliares do gerativismo, como a teoria dos papéis temáticos, são deslocadas para a $f$-seq. Desse modo, a arquitetura apresentada é também delineada para capturar estruturalmente um conjunto de papéis semânticos que identifica a função que cada argumento desempenha no desenrolar do evento. De acordo com Ramchand (2017), as generalizações a respeito do domínio acional e da estrutura temática convergem e esse fato seria uma verdadeira conspiração caso ambos os tipos de generalização não seguissem dos mesmos fatos 
sobre a estrutura sintática. Tendo isso em vista, a autora propõe que os papéis que os argumentos desempenham no evento sejam atribuídos localmente, a depender da posição estrutural que o argumento ocupa. Com isso, as projeções de iniciação (initP), processo (procP) e resultado (resP) formam sua própria estrutura predicacional, sendo a posição de especificador preenchida pelo argumento que desempenha o subevento (INITIATOR, UNDERGOER e RESULTEE, respectivamente) e a posição de complemento saturada pelo sintagma que descreve ("oferece o conteúdo") (d)esse subevento. Coordenação de Apoio à Pesquisa

Esses papéis predicacionais podem ser acumulados por um único argumento e essa possibilidade surge como consequência de uma outra regra nanossintática: a operação de Spell-out Sintagmático (Phrasal Spell-Out) que também distingue a Nanossintaxe de modelos como a Cartografia e a Morfologia Distribuída. O Spell-out Sintagmático prevê que nódulos não terminais sejam também alvo do processo de Spell-out. A motivação para a postulação de tal operação é a existência de línguas em que um único morfema carrega a informação de diferentes núcleos funcionais, como ocorre com a desinência verbal no português brasileiro, em que toda a informação estrutural '[tempo] $>$ [aspecto] $>$ [modo]' é realizada por meio de um único sufixo. Outro exemplo é o morfema '-lüü' do mongol, que carrega os terminais espaciais de '[escala] $>$ [alvo] $>$ [lugar] $>$ [AxPart]' (PANTCHEVA, 2011, p. 98). Pensando no domínio acional, em eventos de atividade inergativos, por exemplo, o argumento não apenas desencadeia o evento denotado pelo predicado, como também o desempenha. Desse modo, em uma sentença como "Joana correu”, Joana receberia o papel composto de [INITIATOR , UNDERGOER ${ }_{\mathrm{i}}$ ]. Em um evento achievement, como "Joana quebrou o vaso", Joana é responsável por dar início à eventualidade, no entanto, é "o vaso" que passa por uma mudança que culmina em um estado final, compreendido normalmente como "quebrado". Nesse caso, o objeto da sentença recebe o papel de [UNDERGOER ${ }_{\mathrm{i}}$, RESULTEE $_{\mathrm{i}}$ ].

É possível observar, com essa exposição sobre a Sintaxe de Primeira Fase, que a Nanossintaxe nos oferece um sistema bastante elegante para tratar de questões do domínio dos eventos e de sua relação com a estrutura argumental, eliminando, por exemplo a necessidade de se postular relações semânticas no léxico e regras de ligação desse nível da gramática com a sintaxe superficial. Assim, com base no que foi discutido, podemos derivar as classes acionais por meio das seguintes estruturas ${ }^{14}$ :

A) Estados: [initP $\{$ HOLDER $\}$;

B) Atividades: [initP $\left\{\right.$ INITIATOR $\left._{\mathrm{i}}\right\}>\operatorname{procP}\left\{\mathrm{UNDERGOER}_{\mathrm{i}}\right\}>$ pathP];

C) Achievements: [(initP $\{$ INITIATOR $\})>\operatorname{procP}\left\{\mathrm{UNDERGOER}_{\mathrm{i}}\right\}>\operatorname{res} \mathrm{P}$ $\left\{\right.$ RESULTEE $\left._{\mathrm{i}}\right\}>$ boundP];

D) Degree achievements: [(initP $\{$ INITIATOR $\})>$ procP $\{$ UNDERGOER $\}>$ boundP > scale];

14 Os conceitos apresentados entre chaves $(\{\})$ correspondem aos papéis aspectuais de cada projeção; o símbolo '>' indica que o elemento à esquerda é hierarquicamente superior ao que aparece à sua direita e as chaves delimitam a estrutura. 
E) Accomplishments: [initP $\{$ INITIATOR $\}>\operatorname{procP}\left\{\mathrm{UNDERGOER}_{\mathrm{i}}\right\}>$ boundP $>$ pathP];

F) Semelfactivos: [initP $\left\{\right.$ INITIATOR $\left._{\mathrm{i}}\right\}>\operatorname{procP}\left\{\right.$ UNDERGOER $\left._{\mathrm{i}}\right\}>\operatorname{resP}$ $\left\{\right.$ RESULTEE $\left._{\mathrm{i}}\right\}$.

Antes que passemos à investigação da causativização no $\mathrm{PB}$, uma última questão precisa ser mencionada a respeito da estrutura dos itens de vocabulário e sobre o modo como esses elementos são inseridos na estrutura. Seguindo Starke (2009), podemos dizer que as árvores construídas pela sintaxe, exemplificadas pelas diferentes configurações das classes acionais apresentadas acima, são estocadas no léxico e pareadas com informação fonológica e conceitual, que corresponde ao conteúdo enciclopédico ou de conhecimento de mundo. Um verbo como 'correr', por exemplo, que pertence à classe dos verbos de atividade, teria uma entrada lexical como $</$ correr/, [initP $>$ procP $>$ pathP], modo de movimento $>$.

Nesse modelo, o léxico pode ser acessado após a inserção de cada traço na estrutura (i.e., nas projeções intermediárias), o que configura um ciclo. Nesse sentido, a operação de Spell-out é cíclica e regida por algumas regras. Um item de vocabulário, por exemplo, só pode identificar um determinado terminal caso seja compatível em diferentes níveis com aquela posição: (i) o elemento deve conter em sua entrada um constituinte que contenha o terminal-alvo, podendo ser um Superconjunto da estrutura pretendida (contrariamente ao que se postula em MD); (ii) todo terminal sintático deve estar lexicalizado ao final de cada ciclo (Princípio da Lexicalização Exaustiva Cíclica); e, (iii) em caso de competição, o item que contiver o menor número de terminais não utilizados vence (Princípio do lixo minimizado). Além disso, para Ramchand (2008), o conteúdo enciclopédico da entrada precisa ser compatível com o conteúdo do traço que pretende lexicalizar.

Com isso, temos um maquinário bastante simples que nos permite investigar a fundo as estruturas dos diferentes eventos em língua natural. Assim, podemos chegar até os elementos subatômicos das classes acionais e explorar, nesse domínio, quais são os fatores que licenciam um determinado predicado a receber uma interpretação de causalidade. Na próxima seção, investigaremos algumas sentenças do PB com base nos pressupostos aqui delineados. Esperamos, desse modo, oferecer um tratamento interessante para o processo de causativização no $\mathrm{PB}$, que isole propriedades mais finas do domínio acional e permita a explicação de um amplo conjunto de dados.

\section{Investigando a causativização no PB dentro da Nanossintaxe}

Nesta seção, investigaremos qualitativamente sentenças que passaram pelo processo de causativização a partir de predicados não causais. Como trabalhamos com o método hipotético-dedutivo, muitas das sentenças investigadas foram construídas por nós, com base em nossa intuição enquanto falantes do PB, porém, apresentamos também algumas 
construções advindas do português escrito para ratificar a existência do fenômeno, uma vez que, conforme dito na introdução deste trabalho, podemos encontrar variação dialetal em relação aos julgamentos oferecidos. Tendo isso em vista, antes de iniciarmos a discussão, é importante relembrarmos os objetivos desta pesquisa: pretendemos compreender (i) o funcionamento do processo de causativização; (ii) o papel de diferentes módulos da gramática na construção de um significado causativo; (iii) as restrições específicas do PB sobre esse fenômeno; e (iv) as relações novas e atípicas que são desencadeadas entre o sujeito e o objeto dos predicados causativizados nessa língua. Para alcançarmos os objetivos assim delineados, tomemos as seguintes sentenças.

(30) O piloto voou o avião por debaixo de uma camada de nuvens a cerca de 1.000 $\mathrm{ft}$ de altura AGL e isto numa região montanhosa ${ }^{15}$.

(31) A agência desfilou suas melhores modelos em Paris.

Em ambas as sentenças, a composição do verbo com seus argumentos denota um evento de atividade, que pode ser interpretado basicamente como um processo de 'voar' e um processo de 'desfilar' desencadeado pelo argumento em posição de sujeito. Parafraseando o significado das sentenças dadas, em (30) entendemos que "o piloto fez o avião voar", e tal fato, inclusive, parece ir contra as expectativas do falante, dado que a sentença é finalizada com a construção "e isto numa região montanhosa". Essa observação, de nível pragmático, pode evidenciar uma pista sobre o contexto no qual a causativização pode ser licenciada: o argumento original do verbo parece ser forçado a desempenhar o evento, não sendo capaz de iniciá-lo ou desenvolvê-lo sozinho. Em (31), analogamente interpretamos que "a agência fez as modelos desfilarem", ou seja, o argumento INITIATOR afeta, de algum modo, o argumento UNDERGOER que é de algum modo compelido a desempenhar o evento denotado. De um ponto de vista semântico-conceitual, tanto 'voar' quanto 'desfilar' são predicados que indicam um modo de movimento; considerando a configuração do modelo nanossintático, essa informação deve ser, necessariamente, especificada no nível enciclopédico. Desse modo, a entrada lexical de 'voar' e 'desfilar' deve ser representada pela seguinte tripla genérica, sendo que apenas o conteúdo fonológico seria distinto entre ambas: $<$ / informação fonológica/, [initP, $>$ procP $>$ pathP], modo de movimento $>$. Dado que os verbos em questão são inergativos, na Nanossintaxe sua estrutura seria distinta da dos verbos inacusativos por exigir a presença do núcleo de iniciação [init], desse modo, o argumento que inicia o evento é o mesmo que toma parte em seu desenvolvimento, por esse motivo, INITIATOR e UNDERGOER seriam coindexados na estrutura desses verbos, por meio da operação de Spell-out Sintagmático. Assim, com base nessas informações, podemos decompor os exemplos citados (de um modo simplificado) do seguinte modo:

15 Disponível em: http://www.aopa.pt/52-operacional/cronicas-de-seguranca-aeronautica/726-seguranca-aeronauticano357. Acesso em: 2 set. 2019. 
Figura 2 - A Nanossintaxe do domínio acional:

uma modificação de Ramchand (2008)

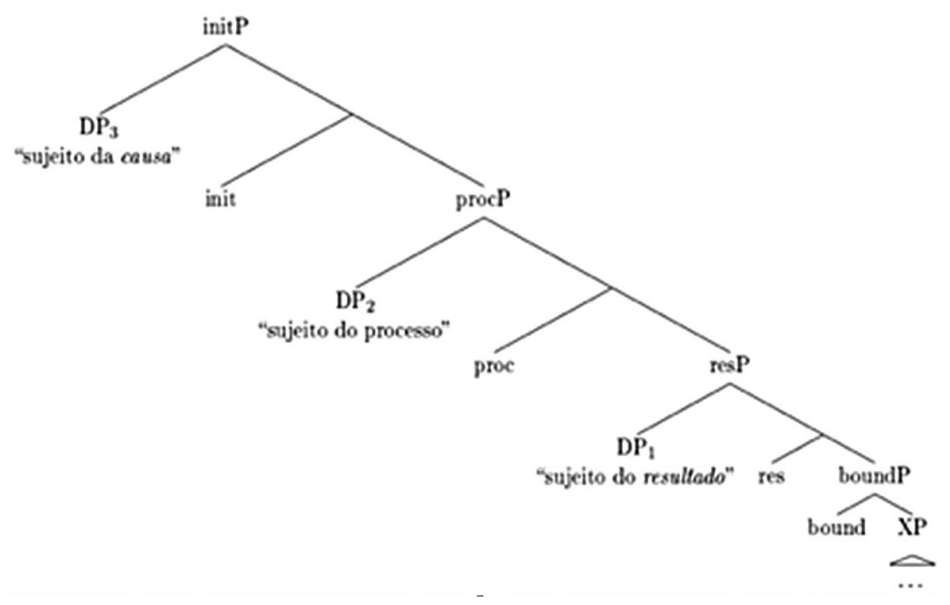

Fonte: Adaptado de Ramchand (2008, p. 39).

Com essa estrutura, é possível explicar alguns dos problemas encontrados na análise da causativização em PB, elencados na segunda seção deste trabalho. Conforme dissemos na seção anterior, a classe das atividades é identificada pelos sintagmas de iniciação, processo e trajetória (initP $>$ procP $>$ pathP). Além disso, afirmamos, seguindo Ramchand (2008), que os papéis de INITIATOR e UNDERGOER devem ser coindexados na estrutura, dado que o argumento que desempenha uma atividade inergativa não apenas participa do processo denotado pelo predicado, como também dá início ou desencadeia esse evento. Assim, como os verbos em (30) e (31) são predicados inergativos, para que haja a causativização é necessário, primeiramente, que a posição de INITIATOR obrigatória nesses verbos fique livre para receber um novo argumento que atuará como causador da eventualidade. Na Nanossintaxe, essa manobra é permitida por meio da subassociação do núcleo relacionado a esse especificador, que deve ser independentemente identificado dentro da fase. Como [init] é o terminal mais alto da hierarquia, ele pode ser ignorado na computação sem ferir a Condição de Âncora, desse modo, subassociando-se o núcleo de iniciação da raiz, toda a estrutura de initP fica livre para o Spell-out. No PB, o evento de causa, representado na Primeira Fase pela iniciação, é externalizado por um item morfofonologicamente nulo $\left(\varnothing_{\text {CAUSA }}\right)$, que línguas como o japonês e o finlandês identificam com morfemas explicitamente realizados. Por conseguinte, sendo o núcleo de iniciação realizado no Spell-out, considerando-se o Princípio da Lexicalização exaustiva cíclica, a posição de especificador pode ser também preenchida por um novo argumento.

Ou seja, a relação de causalidade entre dois eventos causa [init] e efeito [proc] pode emergir quando initP não é identificado pela mesma raiz verbal que denota $o$ 
"resultado" da causa, o efeito. Com isso, não se afirma de modo algum que o processo de causativização depende exclusivamente da disponibilidade de uma posição estrutural para um argumento causador. Note-se que o que está em primeiro plano na discussão é a identificação do núcleo de iniciação, isto é, a causativização depende, sobretudo, da inserção de um novo evento do tipo causa na estrutura, ao qual, acidentalmente, o PB exige a associação de um argumento causador (INITIATOR). Quando falamos, portanto, da causativização de predicados que já possuam um argumento externo (=INITIATOR), a ideia que temos a respeito de o argumento "original" do predicado parecer ser deslocado para a posição de objeto direto é, na verdade, uma ilusão. Afinal, a menos que se trate de uma eventualidade de estado, cujo único terminal de identificação é [init], o argumento de um predicado intransitivo já estará também na posição de UNDERGOER, relacionada tradicionalmente ao objeto direto do verbo. Em suma, quando o processo de causativização ocorre, o único argumento de um verbo intransitivo não muda de posição na estrutura sintática, ele apenas subassocia seu traço mais alto de iniciação, quando se trata de um verbo inergativo. Com isso explicamos elegantemente a reorganização argumental que parece ocorrer quando um verbo não causativo é interpretado enquanto causal.

Tendo explicado como um novo argumento pode ser inserido e computado nesse tipo de estrutura, que teria apenas uma posição de argumento externo a ser preenchida, não esclarecemos, contudo, quais são as restrições para que um inergativo causativize, apenas demonstramos o que ocorre na sintaxe quando o fenômeno é licenciado. Para tanto, podemos investigar a estrutura de verbos pertencentes a essa classe que bloqueiam sistematicamente uma interpretação causativa. Conforme as sentenças abaixo demonstram, de um modo geral, predicados que especificam em seu conteúdo léxico-enciclopédico algum tipo de movimento ou mudança ou, então, que identificam os núcleos de [place] e [path] licenciam uma interpretação causativa, ao passo que predicados que não denotam essas noções bloqueiam sistematicamente a causativização, como é o caso de 'sorrir', 'tossir' e 'piscar', todos predicados que denotam eventos semelfactivos.

(32) *O palhaço sorriu a plateia (com a piada).

(33) *O remédio tossiu a Joana.

(34) *Joana piscou sua filha.

Os eventos semelfactivos são identificados pela hierarquia [initP $>$ procP $>$ resP], uma vez que são iniciados pelo indivíduo que desempenha a eventualidade e são pontuais. Qualquer leitura durativa que essas eventualidades possam apresentar é derivada por s-summing (ROTHSTEIN, 2004). Estruturalmente, a única distinção entre as atividades anteriormente discutidas e os semelfactivos reside no núcleo mais baixo de cada classe: como há uma troca de [path] por [res], tal fato poderia nos levar a crer que o que bloqueia os predicados apresentados de (32) a (34) de serem causativizados é o núcleo de resultado, que contribui para a interpretação pontual do evento. No entanto, 
encontramos alguns semelfactivos, que conteriam o núcleo [res], por serem pontuais, mas que licenciam uma interpretação causativa.

(35) A mãe pulou a criança por cima do muro.

(36) A treinadora saltou o cavalo.

Apesar da presença de [res], essas sentenças são legitimamente interpretadas enquanto causativas, pois podemos parafraseá-las por "a mãe fez a criança pular por cima do muro" e "a treinadora fez o cavalo saltar". Analogamente às sentenças de atividade, esses semelfactivos apresentam em seu conteúdo léxico-enciclopédico uma noção de mudança no espaço, associada também ao sintagma de trajetória 'por cima do muro', e de modo de movimento. Ou seja, parece que mais do que uma restrição estrutural relacionada a algum núcleo da $f$-seq, o que está envolvido para que os predicados sob investigação possam ser causativizados é um elemento do componente gramatical que trata de nosso conhecimento de mundo. Note-se que esse tipo de informação é também armazenada na entrada lexical dos predicados verbais. Para averiguarmos se essa noção não estrutural é de fato relevante para que a causativização seja licenciada, tomemos mais alguns exemplos, dessa vez de predicados inacusativos, os quais são identificados por nanossintaticamente não conterem o núcleo de iniciação [init] e denotarem, usualmente, eventos da classe dos achievements.

(37) *Maria caiu o Pedro de cima do muro.

(38) *Joana chegou Alice na festa.

(39) *Saíram Alice da festa.

Esses predicados, por denotarem eventos achievement, ou seja, eventos pontuais e télicos, carregam o seguimento $[(\text { initP })>\operatorname{procP}>\operatorname{resP}>\text { boundP }]^{16}$ da $f$-seq acional e, além disso, por serem eventos de movimento, codificam uma informação conceitual do tipo “mudança no espaço". O que observamos com esses exemplos, portanto, é que o traço [res] no caso dos achievements bloqueia sistematicamente a causativização, o que acaba sendo independente de esses predicados exibirem uma informação enciclopédica que parece relevante para os inergativos. Muito provavelmente, [res] não permite que os achievements sejam causativizados por essa noção ser incompatível com uma definição de causalidade que leve em conta uma relação temporal extensiva entre a causa e o efeito. Outros verbos inacusativos que não contêm em sua entrada lexical o núcleo [res] permitem a causativização livremente:

(40) Suco verde afina a cintura.

16 O traço de iniciação aparece como opcional por conta da estrutura inacusativa. Note-se que achievements podem compor estruturas transitivas sem maiores restrições. 
(41) O próprio Sigma evoluiu o vírus ${ }^{17}$.

(42) O corticóide engordou o Pedro.

Tanto 'afinar' quanto 'evoluir' e 'engordar' são verbos que denotam eventos de mudança gradativa (contêm [scale], uma noção derivada de [path]), exibindo, assim, a propriedade de monotonicidade. Isto é, cada subparte dessas eventualidades está diretamente relacionada a uma subparte de seu argumento interno e essa relação produz um mapeamento homomórfico que pode ser desencadeado por um indivíduo "causador" (INITIATOR). A propriedade da monotonicidade, no entanto, não é suficiente para licenciar a causativização para esses predicados, pois a classe dos accomplishments, que também exibe essa propriedade, relacionada à incrementabilidade do objeto, não causativiza, basta pensar na agramaticalidade de sentenças como "*Joana construiu Alice a casa" (= Joana fez Alice construir a casa) e "*a mãe desenhou a criança um círculo" (= a mãe fez a criança desenhar um círculo). Os achievements, que parecem bloquear sistematicamente a causativização, podem ser interpretados enquanto causativos quando a propriedade da monotonicidade é computada na sentença a partir de algum elemento que possa introduzir a noção de escala, assim como ocorre com os degree achievements. As sentenças abaixo evidenciam esse fato.

(43) O Brasil caiu o índice de analfabetismo

(44) A alta do dólar despencou o número de viagens ao exterior.

Os dados parecem bastante caóticos, porém, é possível pensar em algumas generalizações para compreender as restrições do PB para o processo sob investigação. Para tanto, é importante lembrar que dentro da Nanossintaxe o léxico não projeta as estruturas, mas é "combinado" a elas a depender de sua informação sintática e de conteúdo enciclopédico, que são pareadas no léxico com a informação fonológica. Por esse motivo, precisamos saber qual é a mínima estrutura necessária para a obtenção de uma interpretação causativa e então investigar quais itens da língua podem ser candidatos a alcançar essa interpretação. Considerando a discussão feita até este momento, assumimos que a causalidade pode ser interpretada com base na seguinte árvore, haja vista que eventos causativos denotam uma relação causal entre um processo de mudança dinâmico desencadeado por um indivíduo INITIATOR distinto do argumento UNDERGOER.

17 Disponível em: http://alvanista.com/solidrenan/posts/3022101-o-triste-mundo-protegido-por-x-e-zero-na-serie-megaman. Acesso em: 2 set. 2019. 
Figura 3 - Relações “temáticas” atribuídas aos argumentos em spec-XP

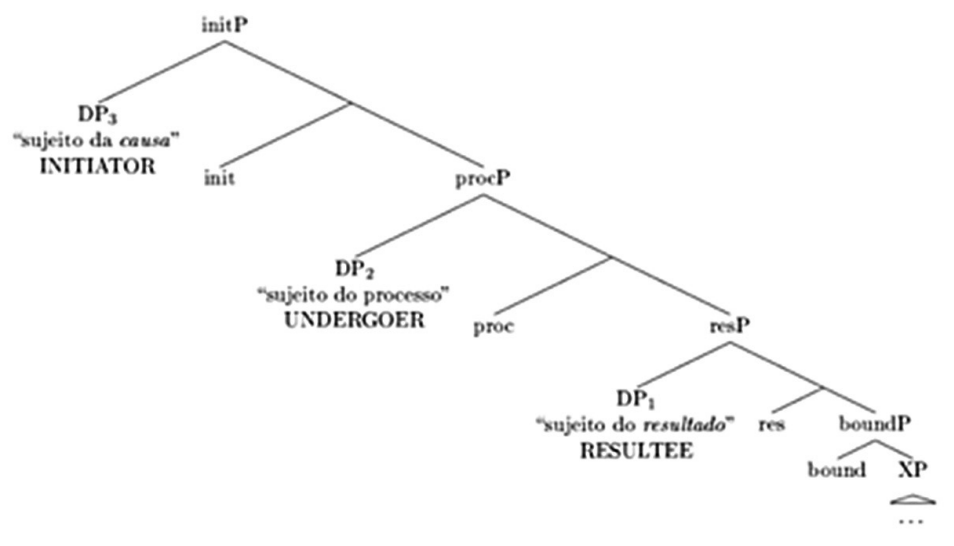

Fonte: Elaboração própria.

Como a Nanossintaxe (CAHA, 2009) assume o princípio do superconjunto, qualquer evento que contenha mais projeções do que iniciação e processo é um candidato para ser interpretado enquanto causativo. Ou seja, a primeira exigência para que um dado predicado causativize é que o evento por ele denotado contenha em sua estrutura a hierarquia [initP $>$ procP], ou apenas o núcleo [proc], dado que essa é a contribuição original do predicado para a interpretação de causalidade: note-se que quando um verbo causativiza, como em "Joana acordou o Pedro", quem de fato desempenha o processo denotado pelo evento é o argumento UNDERGOER, desse modo, o efeito provocado pelo evento de iniciação está necessariamente associado à raiz do verbo que causativiza. Conforme defendemos anteriormente, o núcleo de iniciação [init] é identificado por um morfema nulo, por conta disso, pode entrar na composição junto a eventos que não o identifiquem de saída.

É interessante notar que a existência de um morfema nulo $\left(\varnothing_{\text {CAUSA }}\right)$ na estrutura, pode, inclusive, sustentar nossa intuição de que a natureza do evento de iniciação - a causa - não é especificada: não sabemos o que exatamente o INITIATOR faz para desencadear o evento desempenhado pelo UNDERGOER. Na sentença dada acima, por exemplo, Joana pode ter atirado algum objeto em Pedro ou então pode ter gritado para que ele acordasse. Ou seja, o que exatamente o INITIATOR faz não é relevante, a grande questão é que ele faz alguma coisa que tem um efeito sobre o UNDERGOER, o "obrigando" a participar do evento denotado pelo predicado. Dadas essas observações, podemos prever que estados bloqueiam sistematicamente uma interpretação causativa, por identificarem apenas o núcleo de iniciação na estrutura armazenada no léxico. Além disso, como esse é o terminal mais baixo da hierarquia no caso dessa classe acional, a operação de subassociação seria bloqueada pela Condição de Âncora, impedindo que um núcleo causativo nulo distinto da raiz verbal fosse inserido nessa posição. As sentenças abaixo exemplificam a agramaticalidade de estados causativizados. 
(45) *Joana soube o Pedro matemática. (= Joana fez o Pedro saber matemática)

(46) *Pedro teve Maria uma casa. (= Pedro fez a Maria ter uma casa)

(47) *Joana amou Alice a Maria. (=Joana fez Alice amar a Maria)

(48) *Joana gostou a Maria de brigadeiro. (=Joana fez Maria gostar de brigadeiro)

Com exceção dos estados, portanto, todas as outras classes acionais são candidatas à causativização por apresentarem o núcleo de dinamicidade [proc]. No entanto, a incidência desse fenômeno sobre atividades, achievements, accomplishments, degree achievements e semelfactivos parece ser bastante irregular, dependendo de questões específicas a cada classe. As atividades, que exibem o terminal [pathP] logo abaixo de [procP] causativizam amplamente, apesar de exigirem por vezes um argumento UNDERGOER com baixa volição, conforme pode ser atestado pela comparação entre "o piloto voou o avião até ao chão" e "*o piloto voou o passarinho". Os achievements, que são eventos pontuais [resP], bloqueiam sistematicamente a causativização a menos que um elemento de escala [scale] entre na composição da estrutura, alterando, de certo modo, a acionalidade desses eventos para a classe dos degree achievements, que permitem a causativização sem qualquer outra restrição. Os semelfactivos, que, assim como os achievements, são eventos pontuais, bloqueiam a causativização, a menos que o conteúdo léxico-enciclopédico do predicado exiba alguma noção de mudança espacial, conforme observamos nas sentenças (35) e (36). Os accomplishments, por fim, não permitem uma interpretação causativa em nenhum contexto, muito provavelmente porque sua relação de monotonicidade, dada por [path], dependa mais diretamente de propriedades do UNDERGOER, como definitude. O quadro abaixo busca resumir algumas das propriedades encontradas que parecem ser relevantes para o funcionamento da causativização no português brasileiro ${ }^{18}$.

Quadro 1 - Propriedades relevantes para o processo de causativização

\begin{tabular}{|l|c|c|c|}
\hline \multirow{4}{*}{ INERGATIVOS } & CLASSE ACIONAL & $\begin{array}{c}\text { ESTRUTURA } \\
\text { NANOSSINTÁTICA }\end{array}$ & $\begin{array}{c}\text { LICENCIA } \\
\text { CAUSATIVIZAÇÃO? }\end{array}$ \\
\cline { 2 - 4 } & ATIVIDADES & {$[$ init $>$ proc $>$ path $]$} & SIM \\
\cline { 2 - 4 } & SEMELFACTIVOS & {$[$ init $>$ proc $>$ res $]$} & $\begin{array}{c}\text { apenas quando denotam } \\
\text { movimento espacial }\end{array}$ \\
\hline \multirow{3}{*}{ INACUSATIVOS } & ACHIEVEMENTS & {$[$ proc $>$ res $>$ bound $]$} & $\begin{array}{c}\text { apenas quando denotam } \\
\text { mudança em uma dada } \\
\text { escala }\end{array}$ \\
\cline { 2 - 4 } & DEGREE & [proc $>$ bound $>$ scale $]$ & SIM \\
\hline
\end{tabular}

Fonte: Elaboração própria.

18 Dado que os accomplishments são denotados por verbos transitivos, não os colocamos no quadro; de todo modo esse tipo de evento não licencia uma interpretação de causalidade em nenhum contexto, assim como os estados. 
Tomando os dados apresentados, podemos dizer, como síntese, que dentro desta proposta, inacusativos e inergativos apresentam estruturas que se distinguem pela presença ou não de [init] em suas nanoestruturas. Assim, verbos inacusativos codificariam estruturas como $\left[\right.$ procP $\left\{\right.$ UNDERGOER $\left._{i}\right\}>\operatorname{resP}\left\{\right.$ RESULTEE $\left._{\mathrm{i}}\right\}>$ boundP] ou [procP $\{$ UNDERGOER $\}>$ boundP $>$ scale], enquanto verbos inergativos codificariam estruturas como [initP $\left\{\right.$ INITIATOR $\left._{\mathrm{i}}\right\}>\operatorname{procP}\left\{\mathrm{UNDERGOER}_{\mathrm{i}}\right\}>\operatorname{resP}$ $\left\{\right.$ RESULTEE $\left._{\mathrm{i}}\right\}$ ], quando se trata da classe dos semelfactivos, ou [initP $\left\{\right.$ INITIATOR $\left._{\mathrm{i}}\right\}$ $>$ procP $\left\{\mathrm{UNDERGOER}_{\mathrm{i}}\right\}>$ pathP], quando se trata de eventos de atividade. A variação observada nos casos de causativização de tais classes poderia ser explicada, então, a partir da convergência de diferentes características: a ausência de [init] na raiz verbal de inacusativos poderia justificar a maior facilidade de se causativizar esse tipo de predicado; no entanto, os achievements, que pertencem a essa classe, não causativizam em qualquer contexto, tal como os degree achievements. Note-se que é a presença do núcleo [res] que parece impor uma forte restrição para o licenciamento de causativização sobre esses predicados. Tanto os semelfactivos quanto os achievements só podem obter uma interpretação causativa em um contexto bastante específico, relacionado a questões um tanto distintas: semelfactivos causativizam quando no nível enciclopédico denotam um evento de movimento espacial, provavelmente também ligado a alguma noção formal de trajetória, ao passo que achievements causativizam sob uma propriedade de monotonicidade disparada pela presença de um núcleo [scale] na estrutura.

Uma explicação para as restrições encontradas pode ser dada considerando-se a definição de causalidade exposta no início deste trabalho. Dado que uma relação de causalidade exige um evento dinâmico composto por causa e efeito, relacionados temporalmente, a presença de [res], que torna o evento pontual, ou seja, sem extensão temporal, é incompatível com um parâmetro exigido pela causalidade. As atividades e os degree achievements, identificados pelos traços formais de trajetória [path] e escala [scale] causativizam por apresentarem núcleos compatíveis com o parâmetro temporal obrigatório. Tanto [path] quanto [scale] trazem de algum modo para a estrutura um mapeamento homomórfico entre o objeto direto e a extensão do desenrolar do evento. Tendo explicitado algumas das restrições para a causativização em PB, concluimos o trabalho na próxima seção, discutindo alguns dos problemas a serem resolvidos em pesquisas futuras.

\section{Considerações finais}

Neste trabalho, investigamos o processo de causativização no português brasileiro, buscando compreender (i) como se dava a estruturação de uma interpretação causativa decorrente desse fenômeno; (ii) o papel de diferentes módulos da gramática na construção de um significado causativo; (iii) as restrições específicas do PB sobre a causativização; (iv) como seria possível a inserção de um novo evento na estrutura, interpretado como a causa que leva ao evento denotado pelo predicado; (v) o surgimento 
de um novo argumento com o papel de "causador" ou "desencadeador" da eventualidade descrita pelo predicado, associado ao evento causa; e (vi) as relações temáticas atípicas estabelecidas entre o sujeito e o objeto direto do verbo. Para esboçarmos uma resposta a essas indagações, utilizamos o método hipotético-dedutivo e partimos da hipótese de que eram elementos do domínio acional que faziam a diferença no comportamento dos verbos em relação à incidência de causalidade.

Utilizando o ferramental teórico da Nanossintaxe (STARKE, 2009; CAHA, 2009; PANTCHEVA, 2011; RAMCHAND, 2008, 2011, 2017), demonstramos que para um predicado ser interpretado enquanto causativo é necessário que o evento por ele denotado seja de natureza dinâmica, isto é, apresente pelo menos o traço nanossintático [proc]. A relação de causalidade exige dinamicidade e uma conexão entre dois subeventos identificados por raízes verbais distintas ou por argumentos distintos. Como resultado, a classe dos estados bloqueia sistematicamente a causativização, o que é, certamente, a generalização mais poderosa encontrada em nossa análise. Outra questão estrutural interessante é que o evento de causa precisa ser localizado na posição do núcleo de iniciação, desse modo, quando essa posição já está preenchida pela raiz verbal, é necessário que o processo de subassociação ocorra, deixando não apenas [init] livre para receber um item que seja identificado como o evento de causa, como também o especificador INITIATOR livre para receber um argumento causador. É por meio da operação de subassociação, portanto, que as relações temáticas que aparentam ser atípicas são desencadeadas.

Quando pensamos nas restrições específicas do PB para a causativização, o quadro parece ser um tanto quanto confuso e não sistemático. No entanto, é interessante notar que de fato elementos do domínio acional parecem bloquear ou permitir uma interpretação causativa para certos predicados, o que corrobora nossa assunção inicial. Além disso, as restrições formais (relacionadas aos traços funcionais) que se aplicam a classes acionais específicas, discutidas na seção anterior, podem ser compreendidas com base em uma única generalização: são os núcleos baixos da $f$-seq que corresponde ao domínio de construção dos eventos que licenciam o processo de causativização. A presença do terminal [path] e a noção de [scale] permitem amplamente que os predicados sejam interpretados enquanto causativos, ao passo que o núcleo [res] impede sistematicamente o fenômeno da causativização. Outro elemento que interfere na possibilidade de um predicado causativizar ou não é a noção genérica de mudança, presente no nível do conteúdo léxico-enciclopédico, decorrente do conhecimento de mundo dos falantes. Ou seja, há regras, elementos estruturais e elementos advindos da cognição humana mais ampla que, atuando conjuntamente, licenciam o processo de causativização no PB.

Com essa discussão, esperamos ter lançado uma nova luz sobre o fenômeno da causativização, que ainda carece de trabalhos descritivos sobre línguas específicas, como o PB, e de trabalhos translinguísticos que procurem sistematizar as diferenças entre os processos de causativização de distintas línguas. Nesse sentido, a Nanossintaxe aponta um caminho muito interessante para explicar as diferenças translinguísticas 
observadas, tendo em vista que línguas diferentes estocam partes diferentes das estruturas nanossintáticas em seus verbos e morfemas. Logo, enquanto que, em uma língua como o português, um verbo como 'rir' pode carregar uma estrutura [init > proc $>$ res], no finlandês, talvez o item identificado como 'rir' carregue somente [init $>$ proc]. Para que o funcionamento da causativização seja clarificado e melhor sistematizado, defendemos que é necessário adotar um posicionamento teórico e metodológico que considere a articulação da sintaxe, da semântica e do conhecimento de mundo.

\section{Agradecimentos}

As autoras agradecem aos professores Renato Miguel Basso e Aquiles Tescari Neto pela leitura de versões anteriores deste trabalho. Também agradecemos aos pareceristas anônimos pelos comentários e à Coordenação de Apoio à Pesquisa (CAPES) pelo apoio financeiro.

FERREIRA, T.; RAMMÉ, V. The role of low heads in the causative interpretation in brazilian portuguese: some notes on event composition, f-seq and nanosyntax. Alfa, São Paulo, v. 63, n.2, p.421-452, 2019.

- ABSTRACT: In this paper, we investigate the causativization process in brazilian portuguese, seeking to understand the constraints and generalizations that allow us to explain the apparently chaotic data of this phenomenon in this language. In order to reach our goal, we explore the hypothetico-deductive method and hypothesize that there are elements from the aktionsarten domain that determine the verbal behavior in relation with a causative meaning. Consequently, we present a theoretical review of aspectual classes, employing the tools of a recent approach to the architecture of grammar named Nanosyntax (Starke, 2009). Thereby, it will be possible to understand the more fine-grained constraints that the classes of 'states'and 'accomplishments', for instance, impose for the causativization, taking into account 'nano'syntactic and semantic features, such as Initiation, Process, Result and Boundness. We conclude, therefore, that for a predicate to be interpreted as a causative one, the event denoted by it needs to be dynamic in its nature. In addition, we show that the functional sequence (F-seq), in the way it is proposed within the nanosyntactic model, allows us to explain the possible association of more than one syntactic node with the same verbal argument, as well as its underassociation and consequent identification with a null causative nucleus, as it happens to be the case in brazilian portuguese causativization.

- KEYWORDS: Causativization. Event composition. Aktionsarten. Nanosyntax. Functional hierarchy of the verbal domain. 


\section{REFERÊNCIAS}

AGUIAR, T. Assimetria causal: um estudo. Kriterion, Belo Horizonte v. 44, n. 108, p.279-289, 2003.

AMARAL, L. A causativização de verbos inacusativos. Belo Horizonte, 2009. Relatório Final de Iniciação Cientíca na Faculdade de Letras da UFMG.

BASSO, R. Telicidade e detelicização: semântica e pragmática do domínio tempoaspectual. 2007. 288f. Dissertação (Mestrado em Linguística) - Instituto de Estudos da Linguagem, Universidade Estadual de Campinas, Campinas, 2007.

BASSO, R. M.; PIRES DE OLIVEIRA, R. Em x tempo e por x tempo no domínio tempo-aspectual. Revista Letras, Curitiba, n. 81, p. 77-97, 2010.

BHATT, R.; PANCHEVA, R. Aspect. 2005. LSA Summer Institute, Class Notes.

BELLETTI, A. Aspects of the low IP area. Structure, Cambridge, v. 2, p. 16-51, 2004.

BORER, H. Structuring Sense: An Exo-Skeletal Trilogy. New York: Oxford University Press, 2005.

CAHA, P. Notes on insertion in Distributed Morphology and Nanosyntax. In: BAUNAZ, L. et al. (ed.). Exploring Nanosyntax. New York: Oxford University Press, 2018. p. 57-87.

CAHA, P. The nanosyntax of case. 2009. 321f. Thesis (Doctor in Philosophiae) Faculty of Humanities, Social Sciences and Education, University of Tromso, 2009.

CAMBRUSSI, M. F. Verbos inergativos itens lexicais de alternância causativoincoativa. Domínios de Lingu@gem, Uberlândia, v. 9, n. 1, p. 13-24, 2015.

CAMBRUSSI, M. F. Alternância causativa de verbos inergativos no português brasileiro. 2009. 196f. Tese (Doutorado em Estudos Linguísticos) - Centro de Comunicação e Expressão, Universidade Federal de Santa Catarina, Florianópolis, 2009.

CINQUE, G. Adverbs and Functional Heads: A Cross-Linguistic Perspective, New York: Oxford University Press, 1999.

CINQUE, G.; RIZZI, L. The cartography of syntactic structures. Studies in linguistics, London, v. 2, p. 42-58, 2008.

COPLEY, B.; WOLFF, P. Theories of causation should inform linguistic theory and vice versa. In: COPLEY, B.; MARTIN, F. (ed.). Causation in Grammatical Structures. New York: Oxford University Press, 2014. p. 11-57.

D’AleSSANDRO, R.; FRANCO, I.; GALlEGO, A. The verbal domain. Oxford: Oxford University Press, 2017. 
DAVIDSON, D. Causal Relations. Journal of Philosophy, New York, n. 64, p. 691-703, 1967.

DÖLlinG, J.; HEYDE-ZYBATOW, T.; SCHÄFER, M. (ed.). Event Structures in Linguistic Form and Interpretation. Berlin: Mouton de Gruyter, 2007.

DOWTY, D. Word Meaning and Montague Grammar. Dordrecht: Reidel, 1979.

ECKARDT, R. Causation, contexts and event individuation. In: HIGGINBOTHAN, J. et al. Speaking of events. New York: Oxford University Press, 2000. p. 105-121.

EMBICK, D. The Morpheme: A Theoretical Introduction. Berlin: Walter de Gruyter, 2015.

FERREIRA, T. L.; RAMMÉ, V. Causativização de verbos de maneira de movimento no PB. In: ENCONTRO DO CELSUL, 11., Chapecó. Anais [...], Chapecó: UFFS, 2014. p. 1-19.

HALE, K.; KEYSER, S. On argument structure and the lexical expression of syntactic relations. In: HALE, K.; KEYSER, J. L. (ed.). The view from building 20. Cambridge: MIT Press, 1993. p. 53-109.

HALLE, M.; MARANTZ, A. Distributed Morphology and the Pieces of Inflection. In: HALE, K.; KEYSER, J. L. (ed.). The view from building 20. Cambridge: MIT Press, 1993. p.111-176.

HIGGINBOTHAM, J. Tense, aspect and indexicality. New York: Oxford University Press, 2009.

HORVATH, J.; SILONI, T. Causatives across components. Natural Language \& Linguistic Theory, Dordrecht, v. 29, n. 3, 2011, p. 657-704.

JACKENDOFF, R. Semantics and Cognition. Cambridge: MIT Press, 1983.

LEVIN, B.; RAPPAPORT-HOVAV, M. Argument Realization. New York: Cambridge University Press, 2005.

LEWIS, D. Causation. Journal of Philosophy, New York, n. 70, p. 556-567, 1973.

LIM, D.; ZUBIZARRETA, M. L. The syntax and semantics of inchoatives as directed motion: the case of korean. In: DEMONTE, V.; MCNALLY, L. Telicity, Change, and State: A Cross-Categorial View of Event Structure. Oxford: Oxford University Press, 2012. p. 212-251.

LYUTIKOVA, E.; TATEVOSOV, S. Causativization and event structure. In: COPLEY, B.; MARTIN, F. (ed.). Causation in Grammatical Structures. New York: Oxford University Press, 2014. p. 279-327. 
LUNGUINHO, M. V. A ordem dos verbos auxiliares: uma análise em termos de traços. 2005. Dissertação (Mestrado em Linguística) - Instituto de Letras, Universidade de Brasília, Brasília, 2005.

KAYNE, R. S. Movement and silence. New York: Oxford University Press, 2005.

KRATZER, A. Building resultatives. In: MAIENBAUM, C.; WÖLLSTEIN-LEISEN, A. (ed.). Event arguments in syntax, semantics, and discourse. Tübingen: Niemeyer, 2005. p. 177-202.

KRIFKA, M. The origins of telicity. In: ROTHSTEIN, S. (ed.) Events and grammar. Dordrecht, Netherlands: Kluwer, 1998. p.197-235.

MARANTZ, A. No escape from syntax: don't try morphological analysis in the privacy of your own lexicon. Working Papers in Linguistics, Philadelphia, p.201-225, 1997.

NEELEMAN, A.; Van de KOOT, H. The Linguistic Expression of Causation. In: EVERAERT, M.; MAREJI, M.; SILONI, T. The Theta System: Argument Structure at the Interface. New York: Oxford University Press, 2012. p. 20-51.

PANTCHEVA, M. Decomposing Path: The Nanosyntax of Directional Expressions. 2011. 285f. Thesis (Doctor in Philosophiae) - Faculty of Humanities, Social Sciences and Education, University of Tromso, 2011.

PARSONS, T. Events in the semantics of English: A study of subatomic semantics. Cambridge: MIT Press, 1990.

PINKER, S. Learnability and Cognition: The Acquisition of Argument Structure. Cambridge, MA: MIT Press, 1989.

PIÑON, C. A finer look at the causative-inchoative alternation. Semantics and Linguistic Theory, Ithaca, NY, v.11, 2001.

PUSTEJOVSKY, J. The syntax of event structure. Cognition, Amsterdam, v. 41, p.47-81, 1991.

PYLKKÄNEN, L. Introducing Arguments. Cambridge: MIT Press, 2008.

RAMCHAND, G. Event structure and verbal decomposition. In: TRUSWELL, R. (ed.) The Oxford Handbook of Event Structure. Oxford: Oxford University Press, 2019. p. 2-35.

RAMCHAND, G. The event domain. In: D'ALESSANDRO, R.; FRANCO, I.; GALLEGO, A. The verbal domain. Oxford: Oxford University Press, 2017. p. 233-254.

RAMCHAND, G. Minimalist Semantics. In: BOECKX, C. (org.) The Oxford Handbook of Linguistics Minimalism. Oxford: Oxford University Press, 2011. p. 1-17. 
RAMCHAND, G. Verb Meaning and the Lexicon. Cambridge: Cambridge University Press, 2008.

RAMCHAND, G.; SVENONIUS, P. Deriving the functional hierarchy. Language sciences, Oxford, v. 46, 2014.

RIZZI, L. The Fine Structure of the Left Periphery. In: HAEGMAN, L. Elements of Grammar. Dordrecht, The Netherlands: Kluwer, 1997. p. 281-337.

ROTHSTEIN, S. Structuring Events: a study in the semantics of lexical aspect. Oxford: Blackwell, 2004.

SCHAFFER, J. The Metaphysics of Causation. The Stanford Encyclopedia of Philosophy, Stanford, Fall 2016. Available at: http://plato.stanford.edu/archives/ fall2016/entries/causation-metaphysics/. Access on: 3 Sept. 2019.

SHLONSKY, U. The cartographic enterprise in syntax. Language and Linguistics Compass, Chichester, v. 4, p. 417-429, 2010.

SILVA, Y. R. B. As causativas sintéticas no português do Brasil: novas evidências a favor da estrutura bipartida do VP. 2009. 134f. Dissertação (Mestrado em Linguística) Faculdade de Letras, Universidade Federal de Minas Gerais, Belo Horizonte, 2009.

SMITH, C. S. The parameter of aspect. Dordrecht, The Netherlands: Kluwer, 1997.

STARKE, M. Nanosyntax: A short primer to a new approach to language. Nordlyd, Tromso, v. 36, n. 1, 2009. Special issue on Nanosyntax.

TALMY, L. Toward a cognitive semantics. Cambridge: MIT Press, 2000.

TENNY, C.; PUSTEJOVSKY, J. Events as grammatical objects: The converging perspectives of lexical semantics and syntax. Chicago: University of Chicago Press, 2000.

TRAVIS, L. Event Phrase and a theory of functional categories. In: ANNUAL CONFERENCE OF THE CANADIAN LINGUISTIC ASSOCIATION, 1994, Toronto. Proceedings [...], Toronto: Working Papers in Linguistcs, 1994. p. 559-570.

VENDLER, Z. Verbs and Times. The Philosophical Review, Durham, v. 66, n. 2, p. 143-160, 1957.

Recebido em 28 de abril de 2018

Aprovado em 11 de outubro de 2018 